\title{
Declining Endoscopic Care by Family Physicians in Both Rural and Urban Areas
}

\author{
Lars E. Peterson, MD, PhD, Urooj Nasim, and Vashisht Madabhushi, MD
}

Using data from 2014 through 2016, we demonstrated a decline in the percentage of family physicians providing endoscopic services in both rural and urban areas. Our findings suggest that forces in the health care system may be influencing the reduction in scope, rather than specific geographic factors. (J Am Board Fam Med 2019;32:460-461.)

Keywords: Endoscopy, Family Physicians, Geography, Health Policy, Rural Health

The scope of practice of family physicians (FPs) has been decreasing over the past decade in core aspects of family medicine such as maternity care, ${ }^{1,2}$ care of children, ${ }^{3}$ and women's health. ${ }^{4}$ During this decline, rural FPs continue to have a broader scope of practice than urban FPs across multiple clinical services. ${ }^{4}$ What remains unknown is whether the declines in care that may be considered a core aspect of family medicine are evenly distributed between rural and urban areas and whether it extends to services outside of the usual training and competency of FPs, with endoscopic services being

This article was externally peer reviewed.

Submitted 19 February 2019; revised 7 May 2019; accepted 7 May 2019.

From the American Board of Family Medicine, Lexington, KY (LEP); Department of Family and Community Medicine, University of Kentucky, Lexington, KY (LEP); University of Kentucky, Lexington, KY (UN); Department of Surgery, University of Kentucky, Lexington, KY (VM).

Funding: LEP was supported by the Federal Office of Rural Health Policy (FORHP), Health Resources and Services Administration (HRSA), U.S. Department of Health and Human Services (HHS) under cooperative agreement U1CRH30041.

Conflict of interest: LEP is an employee of the American Board of Family Medicine. The information, conclusions and opinions expressed in this document are those of the authors and no endorsement by FORHP, HRSA, HHS, or the University of Kentucky is intended.

Corresponding author: Lars E. Peterson, MD, PhD, American Board of Family Medicine, 1648 McGrathiana Parkway, Suite 550, Lexington, KY 40511-1247 (E-mail: lpeterson@ theabfm.org).

\footnotetext{
See Related Commentary on Page 454.
}

one such example. One study from a single residency network found a precipitous decline in provision of sigmoidoscopy from 2000 to 2012 by residency graduates from $42 \%$ to $4 \%$ while the provision of colonoscopies remained around $5 \%{ }^{2}$ Our objective was to determine if the percentage of FPs providing endoscopic services is declining in both rural and urban areas.

We used data from the 2014 through 2016 American Board of Family Medicine Family Medicine Certification Examination registration questionnaire. ${ }^{6}$ If physicians registered for the examination multiple times, their most recent data were included. A representative subset of these FPs answered questions about whether they provided colonoscopy, flexible sigmoidoscopy, or endoscopy. ${ }^{6}$ Primary practice address was geocoded and rural or urban status assigned using the Rural Urban Continuum Codes. ${ }^{7}$ We conducted Cochran-Armitage tests for trend for each service by rural/urban status. The American Academy of Family Physicians Institutional Review Board approved this study.

The response rate was $100 \%$. After excluding physicians living outside the United States and those without geocoded addresses $(n=18)$, our final sample size was 6317. The sample was concentrated in urban areas: 82.9\% urban and $17.1 \%$ rural. Rural FPs provided each of the 3 endoscopic services more commonly than urban FPs (Figure 1). For all 3 services, the relative percentage of rural FPs providing each declined by nearly half. Only colonoscopies by urban FPs did not have a statistically significant decline over time.

The decline in the provision of endoscopic services by FPs has 2 notable implications on the experience 
Figure 1. Percentage of family physicians performing endoscopic procedures by urban/rural location from 2014 through $2016(n=6,317)$. Error bars are standard error.

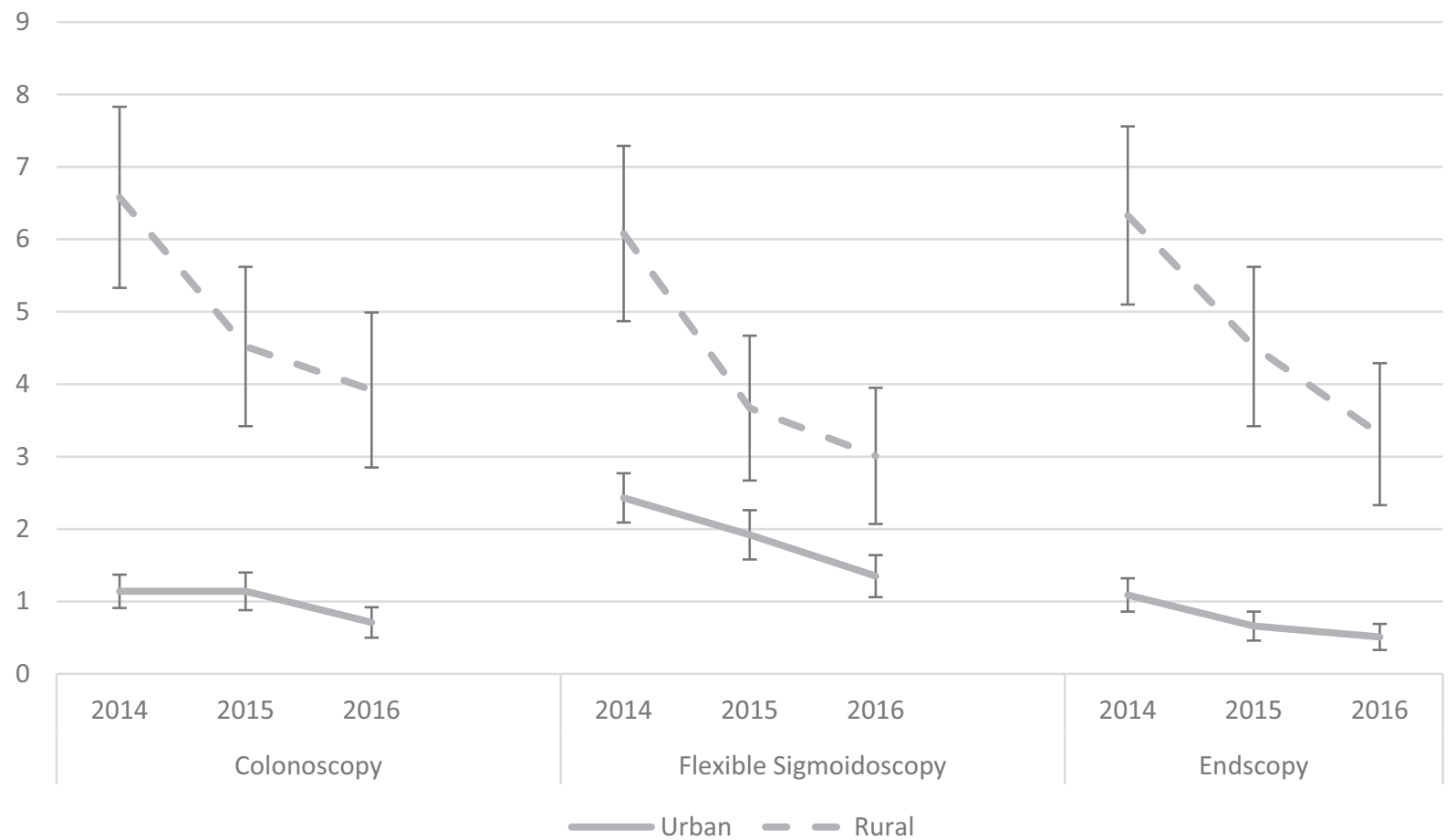

of patients. On one hand, this decrease may increase patient safety if low-volume FPs are no longer providing services. Low procedural volume is independently associated with complications, ${ }^{8}$ and past work found that the decline in FPs delivering babies was mostly from low-volume physicians. ${ }^{9}$ However, our data did not capture volume. On the other hand, our study may indicate declining access to endoscopic services, since the decrease in the scope of practice of FPs is borne not only by FPs in urban areas, where other physicians may provide services, but also by rural FPs, who are crucial for access to health care. Our results also confirm that the erosion of comprehensive care by FPs extends to services beyond the usual training of FPs. Health care systems and FPs should find ways to safely provide endoscopic care for all Americans.

To see this article online, please go to: http://jabfm.org/content/ 32/4/460.full.

\section{References}

1. Tong ST, Makaroff LA, Xierali IM, et al. Family physicians in the maternity care workforce: Factors influencing declining trends. Matern Child Health J 2013;17:1576-81.
2. Weidner AKH, Chen FM. Changes in preparation and practice patterns among new family physicians. Ann Fam Med 2019;17:46-8.

3. Bazemore AW, Makaroff LA, Puffer JC, et al. Declining numbers of family physicians are caring for children. J Am Board Fam Med 2012;25:139-40.

4. Xierali IM, Puffer JC, Tong ST, et al. The percentage of family physicians attending to women's gender-specific health needs is declining. J Am Board Fam Med 2012;25:406-7.

5. Weigel PA, Ullrich F, Shane DM, et al. Variation in primary care service patterns by rural-urban location. J Rural Health 2016;32:196-203.

6. Peterson LE, Fang B, Phillips R Jr, et al. A Certification Board's Tracking of their Specialty: The American Board of Family Medicine's data collection strategy. J Am Board Fam Med 2019;32:89-95.

7. USDA. Rural-Urban Continuum Codes. 2016. Available from: https://www.ers.usda.gov/data-products/rural-urban-continuum-codes/. Accessed February 19, 2019.

8. Lorenzo-Zuniga V, Moreno de Vega V, Domenech $\mathrm{E}$, et al. Endoscopist experience as a risk factor for colonoscopic complications. Colorectal Disease 2010;12(10 Online):e273-e277.

9. Rayburn WF, Manning BK, Petterson SM, et al. Trends in family physicians performing deliveries, 2003-2010. Birth 2014;41:26-32. 